\title{
A Holistic Model for the Development of Entrepreneurial Competencies of the Entrepreneur XXI: The Tree Model
}

\author{
José Luís Soares Ferreira \\ Tree Institute, Lisbon, Portugal \\ Cristina Maria Pinto Albuquerque \\ University of Coimbra, Coimbra, Portugal
}

\begin{abstract}
In the present article it will be critically questioned the traditional entrepreneurship education approaches based on a narrow conception of competency, and their values. Assuming the perspective that to be an entrepreneur is basically an attitude towards life and the world, there proposed holistic, constructivist and experiential processes and strategies for entrepreneurship education. The "entrepreneur XXI”, must be able to undertake a social function of change, so, an economical and social development more human, ethical and intelligent. Under this assumption, the "Tree Model for the Development of Entrepreneurial Competencies", that will be discussed globally in the second part of this article, suggests a dynamic and experiential approach of entrepreneurship education based on the qualification of people's behaviour, self-esteem, competencies and experiences; a profile of key behavioural and performance competencies (root), experimental pedagogical procedures (trunk) and real results within group projects (fruits). This model has been developed during the last decade (2001-2011), using a multidisciplinary research-action procedure, within business, education (at different teaching levels) and social project environments.
\end{abstract}

Keywords: entrepreneurship education, competency, tree model, entrepreneur XXI

\section{Introduction}

The actual financial and economic global crisis, the changes in the labor market and the social integration difficulties of large heterogeneous groups, coupled with the decline of the European social models, set up new challenges for contemporary societies. In this context the "solutions" of the past don't seem to be suitable to provide effective answers to the renewed and complex social and economic problems and expectations. In fact, they seem even self-defeating, not only producing uselessness answers, but also perversing social and

\footnotetext{
José Luís Soares Ferreira, Specialist in Marketing and Entrepreneurship education, President of the Tree Institute (Association for the Economic, Social and Human Development).

Cristina Maria Pinto Albuquerque, Ph.D. in Social Work and Social policy, Professor, Faculty of Psychology and Educational Sciences, University of Coimbra.

Correspondence concerning this article should be adressed to Cristina Maria Pinto Albuquerque, Faculdade de Psicologia e de Ciências da Educação da Universidade de Coimbra, Rua do Colégio Novo, Coimbra 3001-802, Portugal. E-mail: crisalbuquerque@fpce.uc.pt.
} 
economical effects ${ }^{1}$. A paradigmatic shift in the usual ways of thought and action is then indispensable. A critical change anchored in a social ethics perspective, framed by the reinvention of individual and social responsibility, emerges today as both an exigency and a challenge.

Education is crucial for this purpose, namely preparing citizens to understand and to drill an "intelligent world citizenship” (Nussbaum, 2010, p. 81). The adoption of a complex perspective about the world, going beyond modern dualities (social/economic; public/private; local/global) and mere analytical and functional perspectives, is essential to achieve the goal of conceiving a model of economic and social development more human, sustainable and intelligent. In this sense, social and economic domains cannot be dissociated. According to Neurath (as cited in Sapir, 2009, p. 152) any economic choice contains an inevitable social, normative and ethical dimension. In the same way, any social project, organization or initiative produces economic value and must assure self-financial sustainability without being conditioned by public or private stakeholders priorities or interests. This is the main analytical axe inherent to the discussion about entrepreneurship education in this article.

Entrepreneurship is in fact conceived, nowadays, by several authors and international organizations (Crijns \& Vermeulen, 2007; Cuervo, Ribeiro, \& Roig, 2007; EC, 2005, 2010; WEF, 2009), as an important development strategy, combining necessarily a logic of social cohesion and economic equity ${ }^{2}$, by stimulating innovative responses and the involvement of citizens in building social and economic alternatives for individual and/or collective problems. In fact, the stimulus to innovation and initiative, to identify and to exploit, in an intelligent and sustainable way, potential opportunities and scarce resources, as well as the relevance to focus primarily on the strengths and capabilities of the individuals and the communities, are presented, in Europe and abroad, as the operative pillars of a so-called “entrepreneurship culture". The production of really social and economic innovative alternatives, capable to undertake a social function of change, implies primarily a critical revision of the actual economic and social paradigm bases. Consequently it implies also, as it will be argued, a different concept of being an entrepreneur. As Yunus (2008, p. 43) underlined:

In the conventional enterprise theory we created a unidirectional human being to undertake the role of an enterprise leader - the so called entrepreneur. We have isolated him from the rest of the life, the religion, and the emotional, political and social sides. He was dedicated only to one mission, to maximize the profit... Quoting Oscar Wilde, he knows the price of everything and unknown the value of anything.

So, the question nowadays is not about whether or not entrepreneurship should be promoted, but specially about what kind of entrepreneur is needed, or wanted, as well as the social role that he must achieve in the twenty-first century, in order to contribute to the production of a more fair and balanced society. The

\footnotetext{
1 Today its available objective data that allow to assume that serious social and economic gaps are been produced and deepen, especially in the last three decades. Large ratios of unemployment, poverty and unbalanced distribution of wealth, starving millions of people around the world to death, as well as the unbridle exploration of natural resources, which jeopardizes the survival of some regions and even of the human race, are some of the impacts of social and economic development models that need nowadays to be critically revisited.

2 The European Union Green Paper on Entrepreneurship (EU, 2003) set out a range of benefits that can be associated with entrepreneurship. These benefits include contributing to economic growth by job creation and growth, fostering social and economic cohesion particularly in less developed regions to increase their competitiveness and productivity improvements, unlocking personal potential and satisfying a range of social interests by making wealth, jobs and citizens diversity of choice available.
} 
"entrepreneur XXI", as he will be called, should not then replicate the functional models of the last two centuries, but to conceive his action in a holistic and humanistic way.

Upholding this perspective is defended that the quality of being an entrepreneur is basically an attitude towards life and not a mere operative strategy or the result of some applied and measurable skills. It's a culture, a way of thinking, a way of acting, a concept of life and freedom to innovate and to re-act to a culture of fatalism and passivity.

This assumption brings forth structural implications to the goals and processes of entrepreneurship education, which will be discussed along the article. The first one is to conceive entrepreneurship education in the ground of an ethical, complex and critical perspective of life, citizenship and responsibility.

In fact, understanding broadly the concept of entrepreneurship and the entrepreneur XXI as a modern social actor, useful within organizations (public or private), leading social projects and spin-offs, creating businesses or promoting not-for-profit social initiatives, rise issues like: how to contribute to its emergence? Are most of the existing entrepreneurship programs and incentives serving this purpose?

This debate implies a critical analysis of the traditional competence-based training methods to promote entrepreneurship. So, management skills and a performance-/profitable- oriented education are not enough. Holistic competency models (Ferreira \& Tapia, 2010) and new pedagogical strategies are essential to promote a new kind of entrepreneurs that can be engaged with more intelligent and sustainable development processes. A critical thought about the world, an understanding of the articulation between politic, economic and social dimensions, a comprehension of the interdependency between individual and collective needs and choices, are the ground axes for the education that should start in early ages, of more conscious and proactive citizens. As stated by Nussbaum (2010, p.10):

We are not forced to choose between a form of education that promotes profit and a form of education that promotes good citizenship. A flourishing economy requires the same skills that support citizenship, and thus the proponents of what the authors shall call "education for profit”, or (to put it more comprehensively) "education for economic growth", have adopted an impoverished conception of what is required to meet their own goal.

The "Tree Model for the Development of Entrepreneurial Competencies", that will be presented, is settled in these assumptions and tries to associate a profile of key behavioural and performance competencies (root), experimental pedagogical procedures (trunk) and real results (not simulated or merely didactic) within group projects (fruits) (Ferreira, 2010, p. 16).

The second implication of a holistic understanding of entrepreneurship education is, consequently, that there are not necessarily a substantial difference between "business entrepreneurship" education and "social entrepreneurship" education. Although pursuing different missions, the educational ground and the key competences that can stimulate more proactive and conscious citizens, either in business or in social initiatives and roles, are not, in this perspective, substantially different. Some particular skills can be, in more advanced formations, assured by more specialized training modules. However the key competencies and the social ethical ground should be common, especially since early years. The model that will be presented has been developed during the last decade (2001-2011), using a multidisciplinary research-action procedure, within business, education (at different teaching levels) and social project environments. At this moment it is being implemented 
by Portuguese Ministry of Education (National Plan of Education for Entrepreneurship) ${ }^{3}$, the Portuguese Institute of Employment and Professional Training ${ }^{4}$, the High Commissioner for Immigration and Inter-Cultural Dialogue $^{5}$, among other field projects and trainers' training in Portugal and in Ireland (Nurture Tree-A Method for Entrepreneurship Development ${ }^{6}$ ).

To accomplish the analytical goals of the article it will be divided in two parts: in the first one, some conceptions of entrepreneurship education based on a narrow understanding of competencies are critically discussed in order to conceive holistic processes and approaches to promote entrepreneurial attitudes towards life; in the second part, the "tree model" is presented globally as a base to illustrate these holistic processes and methodologies.

\section{Entrepreneurship Education: Critical Questions}

Actually the field of entrepreneurship education is expanding not only in universities and management schools, but also in social organizations. The recent literature highlights in fact the existence of many different types of education and training programmes for entrepreneurs around the world. However, as Damon and Lerner (2008) noted, there is a lack of commonly accepted factors of success and protocols for conducting the necessary evaluations. Those factors could be associated with indicators that fall into four categories: (1) academic knowledge about entrepreneurship; (2) academic performance more generally; (3) business formation and wealth generation, and finally (or mainly); and (4) personal values and aspirations.

Even so, recent research made on the contribution of entrepreneurship education indicates conclusively that it contributes significantly to risk-taking attitudes, to the formation of new businesses (Garavan \& O’Cinnelde, 1994) and to the propensity to be self-employed (Charney \& Libecap, 2000). It also seems to have a positive effect on the perceived feasibility of entrepreneurship, or on entrepreneurial self-efficacy (Lepoutre, Van den Berghe, Tilleuil, \& Crijns, 2010). It was as well demonstrated that positive entrepreneurship education impacts are stronger among students with a positive prior exposure to entrepreneurs experiences (Peterman \& Kennedy, 2003). However, there has been until now relatively little academic studies conducted on the effective and persistent impacts of entrepreneurship education and training, namely on the development of actions and projects, their sustainability, scaling-up and evidences of social and values change (Sexton \& Ksadarda, 1991; McMullan, Chrisman, \& Vesper, 2001).

Considering that entrepreneurship (and inherently entrepreneurship education) is basically an attitude towards life and a dimension of the role that each one must achieve, either in private or in public contexts, then, entrepreneurship is not merely a skill. It implies competencies that are present and are necessary in every field of labour and social life (EU, Focus Group on Key Competences Report, 2005).

This assumption allows to questioning the traditional methods of entrepreneurship training settled in management standard skills and business plans. In fact, management knowledge is not, per si, a predictor of

\footnotetext{
3 National Plan for Entrepreneurship Education, Pertugal http://www.dgidc.min-edu.pt/educacaocidadania/index.php?s=directorio\&pid=19).

4 National Center for Employment and Professional Trainning (Instituto de Emprego e Formação Profissional) (Retrieved from http://www.iefp.pt).

5 High Commissioner for the Immigration and Intercultural Dialogue (ACIDI) (Retrieved from http://acidi.gov.pt).

6 South West Mayo Development Company, Newport, Ireland (Retrieved from http://www.southmayo.com).
} 
entrepreneurial attitudes or even performance. It's possible to agree that business plans are relevant and that (business or social) entrepreneurs can and should elaborate them. But we do not hold any evidences that management skills and business plan training creates (more) entrepreneurial people.

\section{Competency Frameworks: From a Skill-Oriented Education and Training to a Holistic Competency} Approach

The most common approach of the educational model centred on a narrow conception of competencies (skill-oriented approaches) ${ }^{7}$ has its origin in the traditions of functionalist and behaviourist type, popular in the 1960s and 1970s, particularly in the fields of management, human resource development, vocational training and psychological professional orientation (Melton, 1994; Mulder, 2007; Sultana, 2009).

In a context where the "performance culture" tended to establish itself as the prevailing logic, the imposition of standards and measurement processes, of practices and behavioural describers, acquired centrality at the expense of more complex and dynamic approaches. In this sense the determination of "satisfactory performance outcomes" (Jessup, 1991) was central. The behavioural goals would then focus on what "individuals should ultimately be able to do" (Melton, 1994, p. 286) and as such would allow the determination of a set of skills descriptors, more or less standardized and measurable.

However, throughout the 1990s the concept of competency itself, as well as the competency-based education and training, were subject to various and profound critiques (Brown et al., 1994). The most common criticisms were focused on the inability to understand complex activities and behaviours; to ignore personhood values, professional judgements, group processes and social contexts influences (Barnett, 1994; Hager \& Gonczi, 1996), and on the reduction of learning objectives to measurable outcomes, conditioned by predetermined ends, in a kind of "mechanical teaching for the test” (Bates, 1995).

As Martha Nussbaum (2010, p. 9) underlined, by conceiving education programs just oriented by a per formative logic:

We are addressing just one part of the story of how citizens develop (...). The ability to think well about a wide range of cultures, groups, and nations in the context of a grasp of the global economy and of the history of many national and group interactions is crucial in order to enable democracies to deal responsibly with the problems we currently face as members of an interdependent world.

\section{The Rising of Holistic Competency Perspectives}

To surpass the narrow competencies perspective, one fundamental precision was pointed out by Lum (1999). He distinguishes between competence as an educational purpose on the one hand, and competence as a construct that may be provided by new pedagogical strategies and practical application, on the other. Indeed, Lum (1999) noted, like other authors (Shön, 1987; Coburn \& Stein, 2006), either the tacit nature of much of the knowledge that everyone possesses, and the socially constructed nature of the reality and of the position and views of each subject. From this perspective in many areas the "competence performances” cannot be objectified. As the author says, the passage to the practice contains elements that are:

\footnotetext{
${ }^{7}$ It will be considered, for the purposes of this article, the complex notion of competency, worked out by the European Commission (EC, 2005), which includes: (a) cognitive competence (use of theory and concepts, as well as informal tacit knowledge gained experientially); (b) functional competence (skills or know-how); (c) personal competence (knowing how to conduct oneself in specific situations, and (d) ethical competence (the possession of certain personal and professional values).
} 
Entirely dependent upon human agreement; in other words they constitute a reality which is socially constructed through processes of which we remain largely unaware. The addition of these observer-relative features does not add any new material objects to the world because the features added are ontologically subjective (e.g., a performance is only competent insofar as people regard it as such). (Lum, 1999, p. 414)

In fact, the new conceptions of competency-oriented education tend to be more complex and integrated (Hager \& Becket, 1995), considering that the performance can be affected whether by individual attributes and conditions, or/and by the influence of different contexts and situations. In this sense, the competency approach moves away from strictly deterministic behavioural and skills perspectives, accessing to "located" and socio-culturally framed analysis (Brown et al., 1989; Hager \& Beckett, 1995).

Thus, rather than skill standards and outcomes it must considered, in an entrepreneurship education, "broad maps" competencies in contextual territories of education and practice situations (Cooper, 2008). Thus conceiving also that to educate and to learn are processes of "populated loneliness” (Deleuze, 1988). To educate is like throwing a bottle with a message overboard. The facilitator teacher has little control over what is actually learned and how it will be used. Nevertheless he still can enhance that the "message thrown into the sea" can be picked up and understood by the greatest number of recipients.

Under this assumptions becomes relevant the relationship between "knowing” and "doing” which "implies that understanding and experience are in constant interaction-indeed are mutually constitutive” (Lave \& Wenger, 1991, p. 51). So, the strategies of connection and transition between understanding and experience imply necessarily a complex educational model, based on a humanistic philosophy and in a conception of knowledge that integrates, in a holistic and interdisciplinary manner, knowing, doing and being (Delamare-Le Deist \& Winterton, 2005; Sultana, 2009).

\section{An entrepreneurship Education Approach to the "Entrepreneur XXI"}

Like this, being an entrepreneur is to assume a consistent personal and social attitude towards life and the world. Even if an "entrepreneurial education” doesn't generate necessarily entrepreneurs, it can promote, or increase, with renewed pedagogical goals and tools, the possibilities or competencies to be one. Thus we can talk mainly about an "entrepreneurial pedagogy" (Dolabela, 2003): to educate for a more proactive attitude towards life and its limitations and to a more positive perception about the self and about the life contexts. In other words, it is a new sense of personal agency and a new critical freedom (Nussbaum, 2010, p. 141).

To be an entrepreneur XXI implies being able to understand integrated models of social and economic development and to conceive proactive and conscious practices and initiatives. So, according to this conception, entrepreneurship education must, in any case, integrate an ethical dimension (new values focused on positive social responsibility and planet sustainability), a cooperative perspective (including the state, the market, the communities and the persons) and a constructivist vision.

In this sense, entrepreneurship education requires necessarily processes of active learning and a critical mind be able to analyse and to respond to social and economic problems that are global in their scope. The comprehension that we are part of a heterogeneous world enables to associate a factual thought with a complex and dynamic context knowledge, overcoming a merely analytical vision but conceiving the impacts of options and (in) actions in social life. This accountability includes forms of being, behaving, talking, as well as issues such as efficacy, legitimacy, values, connections and responsible power (Wenger, 2009, p. 20). Innovation 
requires in fact flexible, open and daring minds. Reflective and empathic citizens are able to exchange ideas in different backgrounds and to produce "livable knowledge, that is, knowledge that is meaningful because it enables new forms of engagement in the world” (Wenger, 2009, p. 20).

\section{The “Tree Model for the Development of Entrepreneurial Competencies"}

Considering the ground ethical and social perspective that was discussed, the Tree Model aims to carry out the operational basis of an entrepreneurship education, up streaming the most usual training processes in business plans and management. Searching for the basic "building bricks" of an entrepreneurship culture, that can be promoted in school and other social contexts, in other words, trying to identify the minimum personal entrepreneur profile and the pedagogical tools to promote or stimulate it, it was used a research-action methodology applied in the last 10 years $^{8}$. To pin down a minimum profile makes the model simpler and operational and, at the same time, susceptible to replicate in several intervention sectors (schools, businesses, not-for-profit organizations, social projects, and so on), just adapting the specific goals and pedagogical strategies to the initiatives size and complexity and to the ages of the receivers group ${ }^{9}$.

The development of an entrepreneurial culture is a complex, long and holistic process, depending on many factors inside and outside the person, particularly when we work with vulnerable people. Notwithstanding this data confirms that the tree model can contribute positively to engage renewed forms of thinking and acting on proximal or enlarged contexts and problems.

The tree model is thus an open holistic model which relates the person, their motivations, their skills to undertake and their environment (school, enterprise, peers, community), as well as a strong ground education on social and human values. This basic ethical vision is fundamental for the person's formation and integration as an active, responsible and solidary citizen.

The model is conceived figuratively as a tree (see Figure 1). The root is the base where are settled the basic behaviours and performance competencies. The trunk corresponds to the process of competencies development, achieved by action and experiential processes on projects that aggregate personal motivations, interests and/or needs. The branches correspond to the orientation of these projects that must integrate concrete achievements and the active mobilization of competencies. Finally, the fruits are the result or product of the projects. This product must be real and tangible ${ }^{10}$, and in preference, involve some sort of innovation to create value for the person

\footnotetext{
${ }^{8}$ Tree model research: Phase 1: The Entrepreneur (2001-2005). The initial universe for the analysis and design of the competency profile and model was of 128 people (potential entrepreneurs, technical skilled professionals, business managers, people in exclusion context), aged between 25 and 50 years and with qualifications between the basic scholar and graduation. The main goal was to analyze the relationship between (un)successful entrepreneurs and their competencies profile. The research tools were questionnaire, critical incidents, behavior interviews, observation and case studies. Phase 2: Development and evaluation (2003-2009). The model was recognized by the Portuguese Ministry of Education (National plan of education for entrepreneurship, 2004-2009) and began to be developed in several schools and projects. Example-Data for 2007/2008: Overall 99 schools participated in the Project; 357 pupils projects were developed (148 of social emphasis, 104 scientific/technological and 105 with both characteristics); overall 4,153 pupils were involved. Phase 3: Adaptation to basic school, training of trainers and divulgation (2009-2011). Nowadays training of 100 trainers/annually in the Portuguese Institute of Employment and Professional Training; 800 trainees in the program for immigrants to create businesses, in the Portuguese High Commissioner for Immigration and Inter-Cultural Dialogue and internationalization of the model (Ireland).

${ }^{9}$ It was developed namely specific methodologies for youngsters from 6 to 12 years which will not be discussed in this article.

${ }^{10}$ We use the concept of "real” projects to differentiate them clearly from simulated or virtual results, normally used in education and training environments (role playing, theatre, games and so on). A tangible result is exterior to the person, so it can be observed and evaluated using objective procedures.
} 
and/or for others. The connection between the various model components is assured by the personal project methodology.

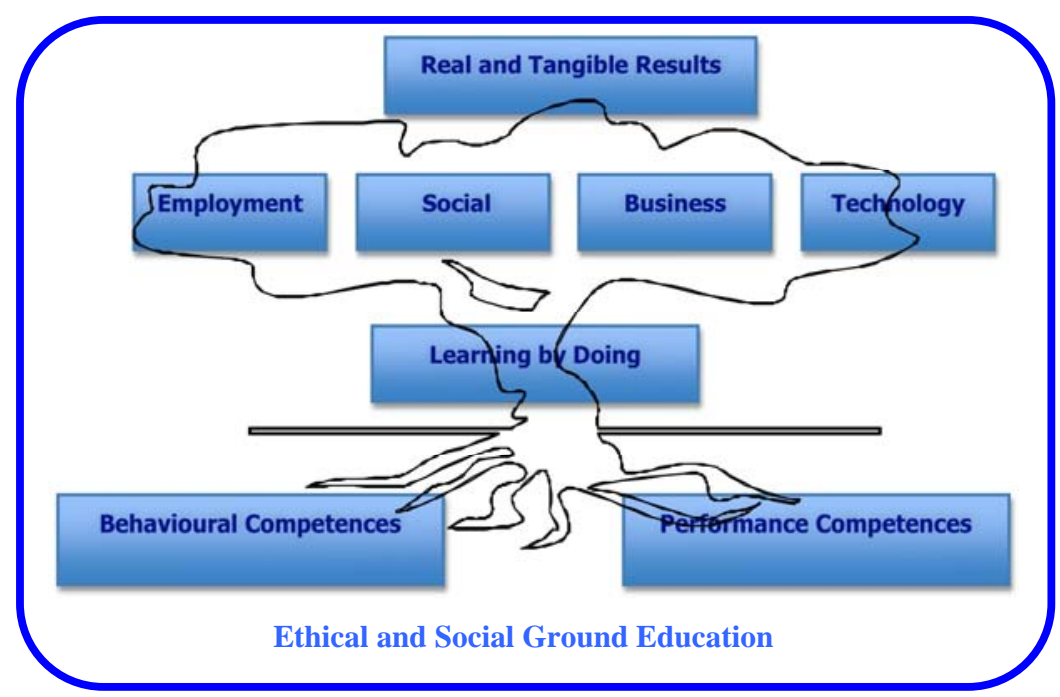

Figure 1. The tree model for the development of entrepreneurial competencies (authors' elaboration).

\section{The Root: Key Competencies}

The competencies are at the summit of the creation of an "entrepreneurial spirit". Through them individuals can in fact achieve the keys to realize their motivations and to acquire and/or use better knowledge and techniques. Like these competencies are at the base of an integrated and dynamic model of entrepreneurial pedagogy because they can be worked out and they allow evaluating, and eventually readjusting, processes and levels of self and action perception. In this model it's possible to work out two types of key competencies: behavioural competencies and performance competencies:

(1) Behavioural competencies are displayed by attitudes and motivations. The acquisition and development of behavioural competencies are the basis of the model. In other words they are the lowest common denominator of an entrepreneur; the competencies that are always present and without which the likelihood of being able to produce action and innovation in a sustainable way are pretty slim. Behavioural competencies should be observable and cross-transferable, i.e., they are open competencies and not skills associated with a specific job or function. The key behavioural competencies are: self-confidence, initiative and resilience. Self-confidence and resilience are the basic pillars to be able to move from a state of inertia to a state of motion, assuring a persistent and structural feature (particularly important in social entrepreneurship proposals) to the initiatives. A confident person, able to withstanding pressures and integrating them without falling apart and jeopardizing their goals, reinforces confidence in a persistent and profound manner.

These three competencies are present in all the entrepreneurs in groups we worked out and can in fact contribute to generate personal and sustainable actions. However, they do not indicate the direction or the quality of such actions. Still it must be remembered that the entrepreneur act and the associated value creation is always relative to the subject starting point and personal context. Like Wenger (2009, p. 25) stated "as learning citizens, we proceed from who we are-our personal histories, connections, networks, vision, aspirations, and position in the landscape of practice - to find forms of participation that increase learning capability”. 
Other kinds of behavioural competencies, in the thoroughfare to the performance competencies, are associated with organization capabilities, cooperative relationships and innovation. The innovation introduces the potential degree of the initiative usefulness associated to value creation. The development of the ability to create new approaches to problems and contexts requires a sense of personal (closely linked to self-confidence and resilience), capable of breaking with conventions and established procedures, as well as a strong focus and persistence to materialize the innovative ideas.

In turn, the organization competencies (in the sense of being able to capture and align external resources of different nature) and the cooperative relationship competencies impute to the initiative, innovative or not, structure and dimension. The higher the ability to acquire and manage external resources, the greater the possibility to conceive larger and more sustainable projects. The co-relations allow in fact to mobilize people around common objectives and, within this mutual adaptation process, to improve the idea and gather new resources, surpassing a competitive and egocentric behaviour.

From this perspective the level of coverage and the potential for projects success depends on the relationship between the behavioural key competencies (see Figure 2).

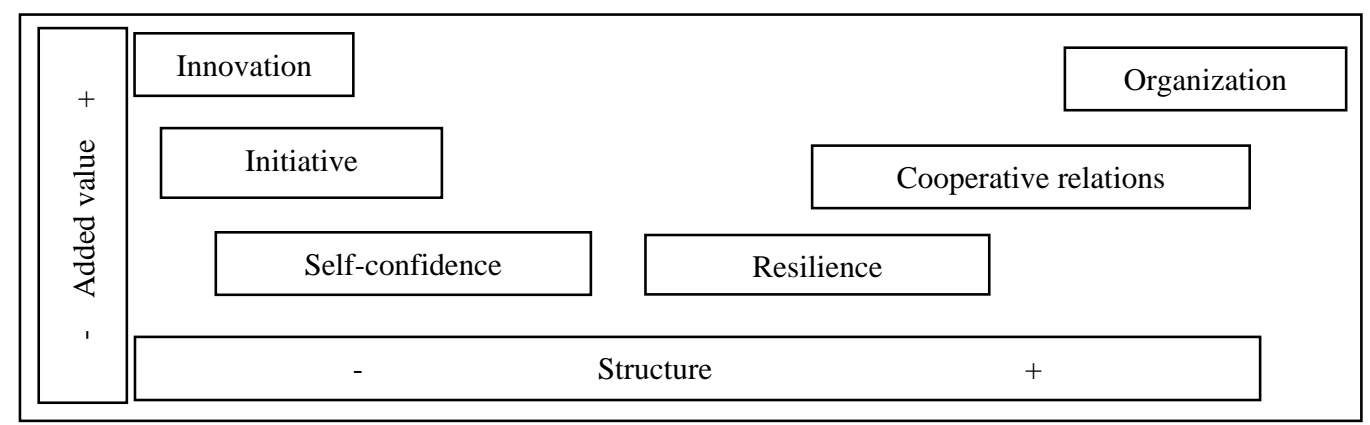

Figure 2. Impact of behavioural competencies on projects (authors’ elaboration).

The structure axe refers to the level of resources (personal and external) mobilization. The added value axe indicates the ability to generate value, considering different possible ways to solve a problem or to find an alternative.

(2) Performance competencies are, in this model, associated with academic and professional performance. They are fundamentally self-built or self-learned. The educational entrepreneurship strategies must mobilize the knowledge and the know-how of the person's universe, exercising and even relearning them in a less formal context ${ }^{11}$.

Particularly important from this perspective it is the conception of the (good) error and the failure. Specially, in new and complex tasks, the question is not whether there will be errors or not, but how to deal with them. Usually it's in the phase of the project execution that the supervisor, generally a person with more experience, intervenes and helps reducing the margins of error by anticipation. However, like this, he removes the opportunity for the participant to learn from his mistakes. In a process of learning-by-doing it must be assured an ecological approach, integrating both the positive and the negative experiences as personal resources. From this

${ }^{11}$ A little illustrative example. In 2008 we asked a group of young entrepreneurs, on a school program, to quantify, in their project, the results that they produced concerning the reduction of water consumption. When they presented their calculus, proving the reduction of water consumption in 5\%, one of the youngsters observed "so, it's for this that maths is useful!". 
perspective there are not truly errors or failures but essentially learning opportunities (Lindsey, 1990).

\section{The Trunk: Personal Project}

But how can be developed these competencies? The pedagogical strategy that proved, by experience learning, to be more suitable is the development of a personal project ${ }^{12}$. The concept of “personal project” is inspired on the pedagogical foundations of the learning-by-doing methodologies. As the precursor John Dewey (1897, article 3, para. 2-3) stated:

Education, (...), is a process of living and not a preparation for future living. I believe that the school represent present life-life as real and vital to the child as that which he carries on in the home, in the neighbourhood, or in the playground.

Although the project designation as personal, it is in fact conceived and designed in groups (Social Learning Spaces, Wenger, 2009), which is an opportunity for developing more cooperative relations. This because the competencies development is not an educational method of people "instruction”, but a personal self-constructing process, through the creation of a conducive learning environment and pedagogy. In this regard Kearney (2009, p. 31) referred that "since learning occurs through interaction with the environment, the learning process, and consequently, the behaviour can be modified more effectively through the planned environment and learning process change”.

Thus, learning-by-doing involves, on the one hand, being able to create an open and defying context and to lead the groups in a non-directive way (that it is also in fact a form of direction). On the other hand, it requires from each person the capacity to experiment a certain idea of himself, to reflect about the experience and its impacts and to achieve the behaviour consolidation or relearning.

\section{The Branches}

The branches are related with the nature of the activities. In this model activities should be real, not simulations, and should be closely linked to the persons interests, values, contexts of life (school, job, business, community) and motivations. Like this the levels of motivation and “want-to-do" are superior (Ceitil, 2006). Being the learning-by-doing a field of real experience the supervisor must define, with the group of participants, action boundaries. In the case of young people education, there suggested activities with social purposes, using, for instance, new technologies.

\section{The Fruits}

The results must be, as it was just said, real. This is one of the distinguishing features of the Tree Model and a critical success factor. Considering this it's possible to identify two levels of results in a dynamic relationship: learning and performance results (see Figure 3).

The performance results are related with the achievement level of personal project goals. Considering the production of real results important (even if it is only in a very small scale) is installed a direct relationship between an idea, an effort and a result. This relationship means that "I participate in the world", and puts people in conscious touch with reality, as an ethical and social actor. On the other hand when there is not a tangible relationship between the person relevant efforts and what really happens to her, she creates the persistent

\footnotetext{
12 The personal project is a pedagogic strategy of action that induces the creation of entrepreneurial initiatives in trainees, as well as inherent experience and learning opportunities (Ferreira \& Tapia, 2010, p. 70).
} 
expectation that in her future the actions to undertake will not produce useful results (Seligman, 1992), and thus, her levels of motivation, self-confidence and initiative will be progressively lower.

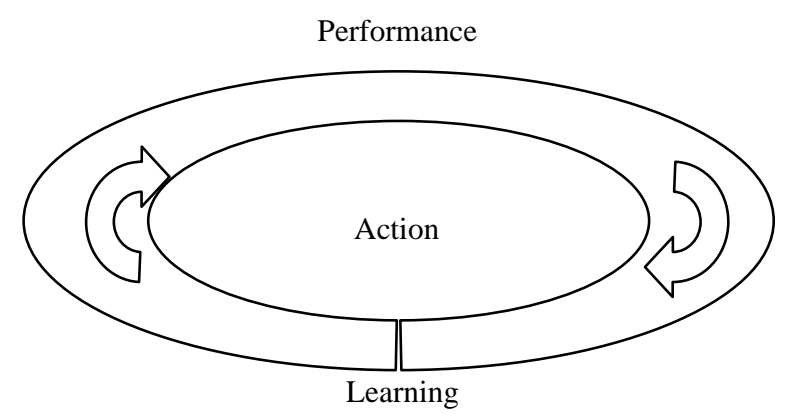

Figure 3. The dynamic relation of results production (authors' elaboration).

\section{Final Remarks}

Not everyone needs to become entrepreneurs, but all members of society need to be more entrepreneurial. In fact, if entrepreneurship is understood as a developmental tool of the potential and energy of each person, the concerning about the promotion of an entrepreneurial attitude, especially among youngsters, should be universal. Like this it is assumed that every person can be an entrepreneur, independently of their age, qualification or economic condition, if they live and interact in a stimulating environment of their potential. So, it can be presumed that there would be more active, aware and responsible citizens if an entrepreneurial pedagogy would be further promoted, especially since early ages.

To achieve this it's important to develop new public policies on this subject. The responsible for educational and training politics and programs must question themselves critically about the values and models of social and economic development that are been promoted under the concept of "entrepreneurship": are the problems just being replicated, or effective new solutions, for a new and better world, are being conceived?

In the same perspective, it's also crucial to promote, namely in the faculties of education and management, the teaching preparation for non-traditional approaches and pedagogies, to train others in the future, and to increase the efficiency and motivation of the learners. Trainers and teachers should act, not only as cultural, holistic and critical thinking promoters, but also as facilitators, to develop a supportive environment to the learning process.

A strong ground ethical education for a conscious and intelligent citizenship, combined with strategies to promote key behavioural and functional competencies, is the base for more active, reflective and innovator citizens. In fact, if the basic pillar of an entrepreneurship attitude is to produce (business or social) value and to be engaged in social and economical change, it's important that students understand more than an amount of standardized skills. It's especially important that they understand critically their role and actions impact in their life context and in the world.

Like this, although some more specialized training courses in particular skills could be useful or necessary in more advanced educational stages, the structural formation is essential to promote the conditions to stimulate either business or social entrepreneurs. In fact both have a social mission to accomplish. So, more than the nature of the produced value (moreover social or financial) it's important to understand primarily that the "how to 
achieve it” responsibly it's crucial that everybody must be implicated in the edification of social and economic sustainable change.

\section{References}

Barnett, R. (1994). The limits of competence. Buckingham: Open University Press.

Bates, I. (1995). The competence movement and the National Vocational Qualifications framework. The widening parameters of research. British Journal of Education and Work, 8(2), 5-13.

Brown, J. S., Collins, A., \& Duguid, P. (1989). Situated cognition and the culture of learning. Educational Researcher, 18(1), 32-42.

Brown, M. et al. (Eds.). (1994). Competence-based training. A collection of readings. Victoria: Deakin University.

Ceitil, M. (Org.). (2006). Gestão e Desenvolvimento de Competências. Lisboa: Edições Silabo, Lda.

Charney, A., \& Libecap, G. (2000). The Impact of Entrepreneurship education: An evaluation of the berger entrepreneurship program at the university of Arizona, 1985-1999. Arizona, T.X.: University of Arizona.

Coburn, C. E., \& Stein, M. K. (2006). Communities of practice theory and the role of teacher professional community in policy implementation. In M. I. Honig (Ed.), New directions in education policy implementation. Confronting complexity (pp. 25-46). Albany: SUNY Press.

Cooper, B. (2008). Continuing professional development: A critical approach. In S. Fraser, \& S. Matthews (Eds.), The critical practitioner in social work and health care (pp. 222-237). London: Sage Publications.

Crijns, H., \& Vermeulen, S. (2007). Survey—How entrepreneurial are our Flemish students? Leuven: Vlerick Leuven Gent Management School.

Cuervo, A., Ribeiro, D., \& Roig, S. (2007). Entrepreneurship. Concepts, theory and perspective. Berlin: Heidelberg.

Damon, W., \& Lerner, R. (2008). Entrepreneurship across the life Span: A developmental analysis and review of key findings. Kansas City: Kauffman Foundation.

Delamare-Le Deist, F., \& Winterton, J. (2005). What is competence? Human Resource Development International, 8(1), 27-46.

Deleuze, G. (1988). Diferença e Repetição. Rio de Janeiro: Graal.

Dewey, J. (1897). My Pedagogic Creed. The School Journal, LIV(3), 77-80. Retrieved from http://edweb.sdsu.edu/people/dkitchen/TE655/my_pedagogic_creed.htm

Dolabela, F. (2003). Pedagogia Empreendedora. São Paulo: Editora de Cultura.

EC (European Commission). (2003). Green paper entrepreneurship in Europe. Retrieved from http://ec.europa.eu/invest-in-research/pdf/download_en/entrepreneurship_europe.pdf

EC (European Commission). (2005a). Towards a european qualifications framework for lifelong learning. Commission Staff WD, SEC 957. Brussels.

EU (European Commission) (2005b). Focus group on key competences report. Implementation of Education and Training 2010 (Work Programme). Retrieved from http://ec.europa.eu/education/policies/2010/doc/basic-skills_en.pdf

EC (European Commission). (2010). New skills for new jobs action now: A report by the expert group on new skills for new jobs prepared for the European commission. Retrieved from http://ec.europa.eu/social/main.jsp?catId=822\&langId=en

Ferreira, J. S. (2011). Entrepreneur XXI. Education for entrepreneurship-New paradigm? International Business and Economics Review, 2, 16-29.

Ferreira, J. S., \& Tapia, A. (2010). Referencial de Formação em Competências Empreendedoras. Lisboa: Instituto de Emprego e Formação Profissional.

Garavan, T., \& O’Cinneide, B. (1994). Entrepreneurship education and training programs: A review and evaluation (part 2). Journal of European Industrial Training, 18(11), 13-21.

Hager, P., \& Beckett, D. (1995). Philosophical underpinnings of the integrated theory of competence. Educational Philosophy and Theory, 27(1), 1-24.

Hager, P., \& Gonczi, A. (1996). Professions and competencies. In R. Edwards, A. Hanson, \& P. Raggat (Eds.), Boundaries of adult learning (pp. 246-260). London: Routledge/Open University Press.

Jessup, G. (1991). Outcomes. NVQs and the emerging model of education and training. London: Falmer.

Kearney, A. J. (2009) . Análise aplicada do comportamento. Lisboa: Porto Editora.

Lave, J., \& Wenger, E. (1991). Situated learning. Legitimate peripheral participation. Cambridge: Cambridge University Press.

Lepoutre, J., Van den Berghe, W., Tilleuil, O., \& Crijns, H. (2010). A new approach to testing the effects of entrepreneurship education among secondary school pupils. Working paper series 2010/01. Leuven: Vlerick Leuven Management School. 
Retrieved from http://www.vlerick.com/en/1298-VLK/version/.../vlgms-wp-2010-01.pdf

Lindsey, O. R. (1990). Precision teaching: By teachers for children. Teaching Exceptional Children, 22(3), 10-15.

Lum, G. (1999). Where's the competence in competence-based education and training? Journal of Philosophy of Education, 33(3), 403-418.

McMullan, W. E., Chrisman, J. J., \& Vesper, K. (2001). Some problems in using subjective measures of effectiveness to evaluate entrepreneurial assistance programs. Entrepreneurship Theory and Practice, 26(1), 37-54.

Melton, F. R. (1994). Competence in perspective. Educational Research, 36(3), 285-294.

Mulder, M. (2007). Competence. The essence and use of the concept in ECVT. European Journal of Vocational Training, 40(1), $5-21$.

Nussbaum, M. C. (2010). Not for profit. Why democracy needs the humanities. Princeton: Princeton University Press.

Peterman, N., \& Kennedy, J. (2003). Enterprise education: Influencing students’ perceptions of entrepreneurship. Entrepreneurship Theory and Practice, 28(2), 129-144.

Sapir, J. (2009). Os buracos negros da ciência económica. Cascais: Produções Culturais.

Seligman, M. E. P. (1992). Helplessness: On depression, development, and death. San Francisco: WH Freeman.

Sexton, D., \& Ksadarda, J. (1991). The state of the art of entrepreneurship. Boston, M.A.: P.W. Kent Publication, Co..

Shön, D. (1987). Educating the reflective practitioner. Towards a new design for teaching and learning in the professions. San Francisco: Jossey-Bass.

Sultana, G. R. (2009). Competence and competence frameworks in career guidance: complex and contested concepts. International Journal of Education and Vocational Guidance, 9, 15-30.

WEF (World Economic Forum). (2009). Educating the next wave of entrepreneurs-Unlocking entrepreneurial capabilities to meet the global challenges of the 21st Century. A Report of the Global Education Initiative. Switzerland: World Economic Forum. Wenger, E. (2009). Social learning capacity. Four essays on innovation and learning in social systems. In A. Vale, E. Wenger, A. Westwood, T. Wolff, \& J. M. Henriques (Eds.), Social innovation: New perspectives (pp. 15-35). Lisboa: GEP/MTSS.

Yunus, M. (2008). Criar um mundo sem pobreza. Difel: Lisboa. 